\title{
Allergen Skin Response Index
}

National Cancer Institute

\section{Source}

National Cancer Institute. Allergen Skin Response Index. NCI Thesaurus. Code C112221.

The ratio measurement of the allergen wheal size to the positive control wheal size in an allergen skin test. 